\title{
SOBRE LAS NUEVAS CONSIDERACIONES EN TORNO A ANDRÉS DE LA CONCHA*
}

\author{
José Guadalupe Victoria
}

De este artista, a quien el padre Burgoa no dudó en designar como "Apeles de este nuevo mundo", conocemos muy poco de su vida personal. A pesar de los esfuerzos hechos por Toussaint, Marco Dorta y otros investigadores, lo único que hasta ahora se sabe es que Andrés de la Concha era natural de Sevi1la, hijo de Francisco de la Concha e Isabel Sánchez, ${ }^{1}$ en enero de 1568 se le autorizó pasar a Nueva España para cumplir el contrato que había firmado el año anterior con Francisco de las Casas -enconmendero de Yanhuitlán-, por el cual se comprometía a realizar el retablo de la iglesia de ese pueblo. ${ }^{2}$

Marco Dorta supone que hacia esa fecha el pintor debía tener entre veinticinco y treinta años de edad. No obstante, según una declaración del mismo artista hecha en 1609 -cuando hizo un reconocimiento al convento de Jesús María de la ciudad de México-, contaba con más de cincuenta años; lo que llevaría a suponer que pudo nacer entre 1554 y $1556{ }^{8}$

Por otra parte, tradicionalmente se ha aceptado que su primera obra en la Nueva España fue el retablo de Yanhuitlán, realizado hacia 1575; e investigaciones recientes prueban que por la misma época trabajó para la catedral de Oaxaca, elaborando el retablo mayor.

Ahora bien, al tratar de relacionar esas fechas -es decir las de la elaboración de aquellos dos retablos y la de su declaración de 1609- tendríamos que aceptar que si se trata del mismo artista, parece no haber tenido la menor idea de su edad al declararla en 1609 , pues resultaría que al momento de firmar el contrato hubiera contado sólo trece años. Lo cual es difícil de creer porque para que Concha fuera llamado a realizar obras de tal envergadura, pensamos, debió ser ya un artista formado, con una madurez comparable a la de Simón Perines o la de cualquier otro de los artistas radicados en la Nueva España.

En fecha que no conocemos, casó con María de San Martín, originaria de la ciudad de México, viuda que era de Felipe Sánchez Sayagos; con ella tuvo dos hijos: Francisco y Andrés, los cuales fueron religiosos, uno fraile agustino y el otro clérigo ${ }^{4}$

Por lo que se refiere a la fecha de su muerte, Efraín Castro Morales piensa

* Este trabajo forma parte de una investigación más amplia que realizamos acerca de Los problemas de la pintura en la Nueva España entre el Renacimiento y el Barroco 1550-1650

1 Enrique Marco Dorta "Noticias sobre el pintor Andrés de Concha" Archivo Español de Arte,

v L, No 199, Madrid, julio-septiembre de 1970, p 343

${ }^{2}$ Ibidem

${ }^{3}$ Martha Fernández García p. 75

4 Documento citado por Guillermo Tovar de Teresa Pintura y Escultura del Renacimiento en México Méxica, Instituto Nacional de Antropología e Historia, 1979, p. 136 
que tal vez tuvo lugar en $1612 ;^{5}$ lo cual parece probar el mismo testamento de su mujer ${ }^{6}$

\section{Elmaestro de Santa Cecilia}

Así designó Diego Angulo Íñiguez al autor de tres importantes cuadros que custodia la Pinacoteca Virreinal de San Diego, a saber: una Santa Cecilia, la Sagrada Familia con San Juan Bautista niño y el Martirio de San Lorenzo. Al tratar de identificar a ese pintor con algunos de los que trabajaron en Nueva España a fines del siglo XVI y principios del XVII dice: "no nos sorprendería que pudiera hacerse con Andrés de la Concha..."?

En fecha más reciente Guillermo Tovar de Teresa, en un estudio comparativo de las pinturas de los retablos de Yanhuitlán, Coixtlahuaca y los tres cuadros de la Pinacoteca Virreinal ha confirmado que se trata de un solo artista. Esta proposición es compartida por Diego Angulo İñguez y Marco Dorta cuando dice que "no hay duda que el maestro de Coixtlahuaca y el de Santa Cecilia, es Andrés de la Concha. La Sagrada Familia, Santa Cecilia y las Tablas de Coixtlahuaca, son de la misma mano, así como también la bellísima 'Sagrada Familia' de la capilla de la Soledad de la Catedral de México" 8 Asunto que confirma - por otra parte- el hallazgo del contrato firmado por Concha para realizar el retablo de Tamazulapan, cuyas pinturas muestran un parecido oficio. ${ }^{9}$

\section{Pintor y escultor}

Las actividades pictóricas y escultóricas desarrolladas por Concha, según el estado actual de las investigaciones, tuvieron lugar entre 1570-75 y 1612 . Casi al mismo tiempo que trabajaba para Yanhuitlán, Concha pintaba el retablo mayor de la catedral de Oaxaca. Este, según noticia recogida por Berlín y dada a conocer por Tovar de Teresa, sería "de tres columnas de alto, con ocho historias en ocho encasamientos", además tendría su sagrario, "con todos sus resaltos, frisos y transpilares" La noticia es bastante escueta y no permite formarse una idea precisa sobre la obra del artista ${ }^{10}$

Tres años más tarde, en 1578, junto con Simón Perines, contrató una obra de escultura con la cofradía de los Evangelistas de la ciudad de México. Se

\footnotetext{
${ }^{5}$ Efrain Castro Morales. "Los maestros mayores de la Catedral de México." p 136.

${ }^{6}$ Documento citado por Guillermo Tovar de Teresa, Op. at, p. 136.

? Diego Angulo Íñiguez. Historia del Arie Hispanoamericano Barcelona, Salvat Editores, 1950, 1. II, $\mathrm{p} s / \mathrm{n}$

${ }^{8}$ Tovar de Teresa, op at, p. 410

${ }^{9}$ Documento citado por Tovar de Teresa, Ibidem, p 457.

${ }_{10}$ Ibidem, p 130 Esta suscinta información coincide con la que publicó Enrique Marco Dorta, relativa a un inventario de la catedral de Oaxaca, hecho en 1598, op at, p 344
} 
trataba de "unas andas con un santo de los Quatro Ebangelistas..." "El contenido de dicho contrato tampoco permite saber cuál era la parte que correspondia realizar a cada uno.

Toussaint había señalado que Concha colaboró con Simón Perines en la realización del retablo mayor de Teposcolula. ${ }^{12}$ Según la información documental en que se basa, la obra pudo haber sido realizada en 1578; tuvo un costo de 4300 pesos de oro común, de los cuales en 1579 todavía restaban por pagar 2024. Por eso Concha, en representación de Perines, levantó una queja en contra del gobernador, alcalde y principales de Teposcolula "deudores a nos los susodichos". Tan grave era el problema que hubo de intervenir el monarca español, quien ordenó el pago de la deuda, "continuando dicho proceso hasta su conclusión, estando fechado a 29 de julio de 1580 '.13

Sin embargo, Tovar de Teresa da a conocer otro documento cuyos datos están en contradicción con los que consignó Toussaint, pues dichos artistas debían entregar la obra "el día de Pascua de la Resurrección primero venidero del año mil y quinientos y ochenta y un años";14 lo cual hace suponer que el retablo debió contratarse por lo menos un año antes. Desgraciadamente el autor no publica íntegro el documento, con lo cual es imposible saber cuándo fue redactado ${ }^{15}$ Como quiera que sea, lo importante es que en dicha obra intervino Concha y que las pinturas fueron de su mano, según puede comprobarse por el estudio comparativo que de ellas se ha hecho.

En 1580 al contratarse el retablo de la iglesia de la Concepción, de la ciudad de México, en el que habian de intervenir: Juan Gómez, autor de la traza; Zumaya para la pintura y el dorado; y Requeña para las esculturas, se menciona a Concha como sustituto de Gómez ${ }^{16}$

Por un documento encontrado en el archivo del juzgado de Teposcolula, se sabe que Concha y Perines continuaban trabajando juntos, pues se comprometieron con los naturales de ese pueblo a "hacer unas puertas para el reta. blo que está en la capilla fuera de la iglesia del templo de este dicho pueblo" " 17 Como se advierte por esta cita, es sumamente difícil saber en qué consistió su obra, la cual, por otra parte, parece haber sido hecha por mero compromiso pues los naturales de Teposcolula habían mostrado su disgusto con

\footnotetext{
"Mariano Muñóz Rivero. "Un documento inédito de interés para el estudio de la escultura colonial en México "Homenaje a don Francisos 7 Gamontda. México, Imprenta Universitaria, 1946, p $337-343$

12 Manuel Toussaint "Tres pintores del siglo XVI Nuevos datos sobre Andrés de la Concha,

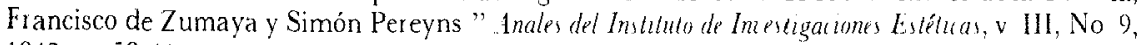
1942 , p 59.61

13 Ilindem

14 Tovar de Teresa, (of) (al, p 130; aunque el autor no especilica de dónde proviene su información

$15 \mathrm{llidem}$

16 Ibutem

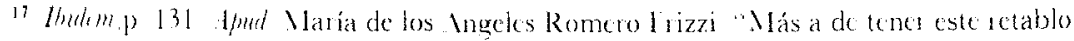


la anterior obra del retablo mayor de la iglesia. La capilla a la cual se alude aquí puede ser la capilla abierta.

En el mismo pueblo, Concha contrató al año siguiente, con el chantre de la catedral de Oaxaca, la elaboración de siete retablos y un sagrario; los cuales serían - añade el documento - "de la misma orden y manera y traza... de la questa e yo hize para el monasterio del pueblo de Yanhuitlán" "18 Tovar de Teresa, sin mencionar alguna fuente señala que Concha otorgó a Perines una carta-poder "para cobrarles el adeudo del retablo a los naturales de Teposcolula". 19

Ahora bien, en 1584 se celebró el contrato para realizar el retablo de Huejotzingo. Fueron invitados a participar en esta obra Pedro de Requeña (escultor), Marcos de San Pedro (dorador) y como pintores colaborarían Simón Perines y Andrés de la Concha ${ }^{20} \mathrm{La}$ participación que cupo a cada uno será discutida en otro lugar.

Hay que añadir que hacia esos años, es decir 1584-1585, Concha participó en la reparación de la catedral vieja de México. Estuvo encargado de realizar el retablo mayor cuyas pinturas fueron hechas por Perines; además elaboró los remates del sagrario del propio retablo y "remató en tres mil pesos, el dorado del artesón de la nave central". ${ }^{21}$

Que el artista trabajaba ampliamente lo prueba el hecho de que, en 1587 , estuviera al frente de dos obras importantes: por un lado se sabe que era solicitado para realizar el retablo mayor de Tamazulapan, y, por otro, levantaba el de la iglesia de Achiutla. ${ }^{22}$

Toussaint pensaba que ese mismo año el artista había construido el altar mayor de la iglesia de San Agustín de México. Sin embargo, considerando el testimonio de Dionisio Rivera Flores - cuyo libro fue publicado en 1599Tovar de Teresa cree que dicha obra debe fecharse años más tarde, entre 1590 y 1599 ${ }^{23}$ También por las nuevas investigaciones sabemos que Concha, en 1593, realizó un retablo para la iglesia de Oaxtepec, Mor ${ }^{24}$

Hasta ese momento Concha parece haberse consagrado casi exclusivamente a trabajos de pintura y escultura; a partir de entonces, como veremos más adelante, iba a ampliar sus actividades al campo de la arquitectura

En 1599 fue requerido para realizar dos cuadros alegóricos: uno de la Fama

18 Ibidem

19 Ibrdem Quizá estos datos, que según Tovar de Teresa provienen del Archivo Cervantes, sean los mismos a que alude Toussaint en su publicacion de 1942

20 Tovar de Teresa, Op Cil, p. 131. Apud. Heinrich Berlín, "The High Altar of Huejotizingo".

The Americas, Washington, D.C., v I, p. 63-73

${ }^{21}$ Manuel Toussaint. Pintura Colontal en México México. UNAM. Insthtuto de Investigaciones Estéthas, 1965 , p. 68

${ }_{22}$ Tovar de Teresa, Op Cul, p 131, 458-459. Apud María de los Angeles Romero Frizzi, Op. Cil

23 Toussaint, Op. Cll, p. 68

24 Tovar de Teresa, Op Cil, p. 132 
y otro de la Victoria, que formarian parte del túmulo funerario erigido a la memoria de Felipe II ${ }^{25}$ Tres años más tarde, en 1602, continuaba trabajando para la catedral de México y, en colaboración con Alonso Franco, construía y pintaba el arco que levantó la ciudad a la entrada del arzobispo de México Fray García de Santa Maria Mendoza y Zúñiga ${ }^{26} \mathrm{Y}$ lo mismo hizo al año siguiente para el arco que se levantó a la entrada del virrey Marqués de Montesclaros. ${ }^{27}$

Las Actas del Cabildo de la ciudad de México mencionan que en 1610, realizó la traza de un retablo dedicado a San Gregorio Taumaturgo, "para la capilla de dicho santo que costeaba el ayuntamiento" ;" el cual no habia terminado aun a fines del año siguiente ${ }^{29}$ Hacia esa misma época, diseñó el retablo de la iglesia de Jesús María, que no llegó a realizar pues Marroqui consigna que "la iglesia se dedicó el 7 de febrero de 1621 ", pero sin el retablo. ${ }^{30}$

El historiador oaxaqueño Antonio Gay apunta la noticia respecto a la última obra pictórica efectuada por Concha, que no fue otra sino la de los cuadros del retablo principal de la iglesia de Santo Dominge de Oaxaca. Dicho retablo "tuvo de costo la suma de 13,000 pesos sin los gastos de transporte desde la ciudad de México donde fue hecho Se colocó en 1612 y, años más tarde, en 1681, fue sustituido por otro más suntuoso que conservaba las pinturas primitivas". ${ }^{31}$ Estas noticias - que parecen fidedignas - quedan en cierta forma invalidadas por el testimonio de la viuda del pintor, cuando afirma que el convento de Santo Domingo de Oaxaca le había embargado sus bienes "a causa de la obligación que otorgó con su marido para hacer el retablo del convento y no haber podido cumplir con ella" 32

\section{Obra arquitectónica}

Echada por tierra, desde hace mucho tiempo, la idea del padre Burgoa, en el sentido de que el artista había sido traído del Escorial para construir el convento de Yanhuitlán, tratemos de ver cuáles fueron sus "ribetes de arquitecto", según la expresión de Toussaint.

Algunos autores como Robert Mullen piensan que se puede atribuir a Concha el diseño de la fachada de esa iglesia dominica. ${ }^{33}$ Atribución que per-

25 Toussaint, Op. (ul, p. 69

26. Ibidem.

27 Ibidem

28 Ibidem

${ }^{29}$ Fernández, Op.Cat, p 84 Apud. José Maria Marroqui, t. III, p 57. La ciudad de México, t. III, p. 57

3i1 Ibidem.

3 Toussaint, op Cit, p. 69

32 Documento citado por Tovar de Teresa, $O p$. Cil, p 136

33 Robert Mullen. Dominican Architecture in the Sixteenth Century Oaxaca. Phoenix, Center for Latin American Studies, Arizona State University and Friends of Mexican Arts, 1975, p. 140 
sonalmente ponemos en duda considerando los argumentos que, a ese propósito, señala Elisa Vargas Lugo ${ }^{34}$

Sólo en la última década del siglo XVI - no se sabe por qué razones - Concha empieza a desarrollar trabajos de arquitecto: en 1597 al obtener el nombramiento de obrero mayor en las obras del Hospital de Jesús y, más tarde, en 1604, cuando el gobernador del Marquesado de Oaxaca lo favorece con el puesto de veedor. ${ }^{35}$

Durante los tres últimos años de dicha centuria se efectuó un concurso para designar maestro mayor del máximo templo metropolitano; cargo que le fue otorgado a Concha "pintor por oficio y muy aventajado, que aunque no sabe cosa alguna de cantería, ha hecho obra de escultura con muy buen crédito, y se tiene por más inteligente para arquitecto que los demás... ". ${ }^{36}$ Ese puesto lo iba a mantener Concha hasta su muerte.

A partir de ese momento se le menciona como maestro de arquitectura, por ejemplo en 1599 en el poder que dio junto con Martín de Solano, "para el cumplimiento de la postura que hicieron en la obra que se ha de hacer en la iglesia de Guadalajara" "87 De qué iglesia se trata y qué obra realizaron es algo que no podemos imaginar.

Conviene insistir en el hecho siguiente: casi todos los trabajos los lleva a cabo en compañía de otros maestros Se trata de "reconocimientos" - como el que hizo a la iglesia del Carmen de la ciudad de México en 1602-; de "inspecciones" a obras de religiosas - tal la de la iglesia de Jesús María, en 1601, que continuó el año siguiente y más tarde en 1609-; de "inspecciones" a obras particulares -por ejemplo las que realizó entre 1604 y 1607 en el Hospital de Jesús-; de "inspecciones" a obras del gobierno - desagüe de la ciudad-; de "tasaciones" - al mismo hospital en 1602-; por último de "avalúos" como el que hizo por encargo del virrey respecto a las fincas de la ciudad con el objeto de obtener recursos para iniciar el mencionado desagüe. ${ }^{38}$

Entre sus obras importantes se cuenta la primera planta de la alcaicería, en las casas del Marqués del Valle, acompañada de la redacción de las condiciones que deberían guardar los compradores de esos terrenos. Dicha planta, según Báez Macías, es anterior a 1611, pues a partir de esa fecha se alude al proyecto elaborado por Concha. En 1615 se decidió cambiarlo por otro de Sebastián Zamorano. ${ }^{39}$

También parece que fue suyo el plano para la iglesia de San Hipólito pues,

\footnotetext{
34 Elisa Vargas Lugo Las Poriadas Réligiósas de México, México. UNAM. Instituto de Investigaciones Estéticas, 1969, p 184

35 Fernández, Op. Cit, p. 79

${ }^{36}$ Ibidem, el subrayado es nuestro

37 Tovar de Teresa, op Cit, p 132

${ }^{38}$ Fernández, Op. Cit y Vicente Riva Palacio et al. Méxzco a través de los siglos, México, Ballescá y Compañía, 1889. T. II, p. 542.

${ }^{39}$ Eduardo Báez Macías. "Condiciones para rematar las tiendas y obras de la Alcaicería 1611." Anales del Instituto de Investigaciones Estéticas, v XIII, n. 47, 1977, p. 99-105, 4 figs
} 
dice Toussaint, en el acta de cabildo con fecha 22 de agosto de 1611, "se ordena que se lleve la planta de ese templo 'pidiéndola a Concha o a quien la tuviere" ". 40

Hasta aquí las noticias que se conocen, por el momento, respecto a sus actividades de arquitecto.

\section{Obras atribuidas}

Desde 1927, Manuel Toussaint pensaba que entre las pinturas que mayor semejanza presentaban con las del retablo de Yanhuitlán, se encontraban las de Coixtlahuaca. Se basaba para ello en el análisis del color y del dibujo, lo que le llevaba a pensar que hubieran sido realizadas "por un discípulo de nuestro pintor, es decir Andrés de la Concha, además - agrega - :" "Comparando cuadro con cuadro resulta una influencia visible y esto nos permite definir las características de cada uno de los dos artistas" "Tratando de encontrar al autor de esas pinturas desecha la posibilidad de que fuese Juan de Arrué, a quien se supone discípulo de Concha, y concluye que "es pues, preciso buscar aún al autor de este retablo". ${ }^{42}$

Sin embargo - según hemos asentado líneas atrás - otros autores se inclinan a otorgar la paternidad de estas pinturas a Andrés de la Concha. Y lo mismo hacen respecto a los tres cuadros conservados en la Pinacoteca Virreinal.

El propio Toussaint y Diego Angulo le atribuyen un cuadro de la Piedad, conservado también en la iglesia de Yanhuitlán, fuera del retablo, si bien Toussaint dice que es posible haya formado parte del conjunto

Otras obras que pueden atribuírsele son las siguientes: una Sagrada Familia Ana y San Foaquin, en la capilla de la Soledad de la catedral de México, y una Virgen del Rosario que existe en la parroquia de Tláhuac, D. F.

Xavier Moyssén, en las notas que hizo a la Pintura Colonial en México, de Toussaint, dice que "suyas deben ser las pinturas que se conservan ahí mismo en la capilla de Santa Gertrudis", es decir en el convento de Teposcolula ${ }^{43}$ Desgraciadamente no conocemos dichas obras y nos abstenemos de atribuírselas a Concha.

\section{¿Dos artistas con un mismo nombre?}

Recientemente, considerando la declaración de 1609 hecha por el pintor, así como las fechas de sus obras de pintura y arquitectura, se ha propuesto la existencia de dos artistas con el mismo nombre: padre e hijo, respectivamen-

\footnotetext{
40 Toussaint, Op. Cit, 69

4I Manuel Toussaint. "Notas sobre Andrés de la Concha." Revista Mexicana de Estudios Históncos, $t$ I, n 1, enero-febrero, 1927, p 26-39.

42 Ibidem

${ }^{43}$ Toussaint, Pintura Colomal en México, p. 252, nota 8
} 
te. ${ }^{44}$ Es decir que habria un pintor que trabajaría entre 1570-75 - fecha tradicionalmente aceptada para la realización del retablo de Yanhuitlán - y 1599 en que llevó a cabo los trabajos para el túmulo funerario levantado a la memoria de Felipe II

Según este mismo parecer, los trabajos del arquitecto comenzarían a partir de 1597 y terminarían hacia 1611; además, por el hecho de que entre esos años no se hable tanto del pintor:

podríamos pensar quizás que el maestro Concha elogiado tantas veces por los cronistas novohispanos gracias a la maestría y calidad de sus pinturas, fue el padre de otro Andrés de Concha que, siguiendo las enseñanzas de su padre, fue pintor y escultor - como declaró el virrey en 1601-, pero que después dedicó su vida a la práctica de la arquitectura. ${ }^{45}$

Nosotros no compartimos esta idea en modo alguno, pues consideramos que las noticias conocidas hasta el momento se refieren a un mismo artista. Con Marco Dorta nos inclinamos a pensar que Concha pudo tener entre veinticinco y treinta años de edad cuando pasó a Nueva España, es decir que habría nacido hacia 1540

Ahora bien, como se sabe Concha fue traído para realizar las obras del retablo de Yanhuitlán. De modo que su formación - en tanto que pintor y escultor - debió ser bastante sólida y tal vez sus conocimientos de arquitectura que no debieron ser pocos, decidió probar trabajos de otro tipo; así se entiende que fuera nombrado maestro mayor de la catedral de México, si bien - se dice- era ante todo "pintor por oficio y muy aventajado"; y, por otra parte, "aunque no sabe cosa alguna de cantería, ha hecho obra de escultura con muy buen crédito, y se tiene por más inteligente para arquitecto que los demás". El hecho de que se diga que "no sabe cosa alguna de cantería" nos lleva a pensar que hasta ese momento no había realizado, aunque fuese de segundo orden, ninguñà óbra de arquitectura; pues al decidirse a darle el nombramiento, las autoridades no podian ignorar los trabajos que hubiere realizado con anterioridad En cambio resalta claramente su calidad de escultor. Además, se sobreentiende que el puesto le fue otorgado en razón misma de su experiencia.

A partir de entonces comienza su "carrera" de arquitecto, aunque siempre sigamos creyendo que ello ocurre en un nivel secundario. Por lo menos eso es lo que permite suponer el tipo de obras en las cuales participó.

También queremos puntualizar un hecho en el que otros autores apenas si insisten: a saber la participación de Concha en obras relacionadas con el Marquesado de Oaxaca: por ejemplo las del Hospital de Jesús Conviene preguntarse a qué se debió esta serie de encargos Nos atrevemos a sugerir

\footnotetext{
44 Fernández, $O p \quad C a t$, p. 76-78

${ }^{45}$ Ibidem.
} 
que quizá nuestro artista mantuvo amistad permanente con los administradores del Marquesado, desde su arribo a la Nueva España. Amistad que quizá se fomentó gracias a las constantes estadías de Concha en la región de Oaxaca.

Volviendo al asunto de por qué nuestro pintor se decidió a trabajar como arquitecto, Toussaint habia señalado que tal vez hubiera obedecido a la competencia que existía entonces en el terreno de la pintura. Nosotros pensamos que no le falta razón pues hay que considerar que, desde la realización del retablo de Yanhuitlán, hasta su nombramiento de maestro mayor de la catedral, habían transcurrido unos veinte años. Para ese entonces el número de artistas establecidos en Nueva España se habia acrecentado; y, por consiguiente, la competencia era mayor.

También es factible que el gusto hubiera cambiado y que el "público" tuviera otras preferencias: "por aquel tiempo Echave Orio estaba en apogeo" 46 Eso llevaría a Concha a explotar sus conocimientos de arquitecto; pero siempre - volvemos a insistir - en un nivel secundario Queremos decir con esto que lo consideramos ante todo pintor y escultor.

Sus últimas obras como tal: el retablo para la capilla del Ayuntamiento y el retablo mayor del convento de Santo Domingo de Oaxaca, serían la prueba más rotunda de cuánto había venido a menos. Respecto a la primera de esas obras, hay que recordar que no la pudo terminar en el plazo señalado, viéndose en la necesidad de pedir:

trescientos setenta y tantos pesos que se le adeudan, mediante fianzas a satislacción, y que él se compromete a terminar el trabajo. Un regidor apoya al artista, atento a sus necesidades y a 'los pleitos que asoman sus deudas'; pero los demás votan porque dos pintores maestros vean la obra y hagan la tesación de lo que falta así proveer. No consta cuál fue el resultado pero se ve clara la decadencia, el fin ${ }^{47}$

Efectivamente, esto último queda probado por el embargo que hizo el convento de Santo Domingo de Oaxaca, de los bienes de su viuda, "a causa de la obligación que otorgó con su marido para hacer el retablo del convento y no haber podido cumplir con ella" 48

\section{Confirmaciones, rectificaciones y nuevos problemas}

En los párirafos anteriores hemos tratado de ordenar cronológicamente las noticias acerca de la vida y la obra de este pintor - conocidas hasta el momento - sin hacer un análisis de su obra en sí; lo cual constituye otro apartado del estudio al que hicimos referencia al principio de este artículo.

tis Toussaint, (op) (il, p 69

47 Iloudem

18 Tovar de Teresa, op (it, p 136 
Gracias a las recientes investigaciones consignadas en la bibliogratía, se han ratificado, por una parte, muchas de las noticias conocidas con anterioridad y, por otra, se confirman varias suposiciones planteadas en torno al artista y su obra. Entre ellas destaca, especialmente, su identificación con el maestro de Santa Cecilia. Consecuencia de ello son las atribuciones de pinturas como las del retablo de Coixtlahuaca y las que se conservan en la catedral de México, además de otra en la parroquia de Tláhuac.

Aspecto notable, también, es la búsqueda documental en torno al pintor, lo que ha permitido reconocer obras fundamentales de su producción; es el caso del conjunto de cuatro pinturas procedentes del antiguo retablo de $\mathrm{Ta}-$ mazulapan.

A decir verdad, son pocas las rectificaciones que, con base en los recientes aportes documentales, pueden hacerse a la bibliografia anterior a 1950. En cambio, se echa de menos un acercamiento más crítico hacia la nueva información; lo cual lleva a que ciertos datos ya conocidos parezcan invalidados y sin mayor fundamento. Por otra parte, se advierte cierta precipitación en el análisis de algunos datos, como en lo referente a la.posibilidad de que haya habido dos artistas con el mismo nombre.

Desde nuestro punto de vista, los problemas que restan por resolver en cuanto a Concha, están más en relación con su obra en sí que con su vida. Uno de ellos esencial por la proyección que pudo tener en el ambiente artístico de Nueva España es el que se refiere a su formación. Enterrada definitivamente la idea de que vino del Escorial, habrá que buscar ese origen en Sevilla, como dijo Angulo, y en el círculo de Luis de Vargas.

Eso en cuanto a la pintura, respecto a la escultura el problema es mayor aun, pues una buena parte de su trabajo no se conserva hoy. A pesar de que Tovar de Teresa piense que pueden atribuírsele las esculturas del retablo de Coixtlahuaca. ${ }^{49}$ Además hay que considerar que muchas de ellas las hizo en colaboración con Perines y, por si fuera poco, también debe tenerse en cuenta la participación, mayor o menor, de sú taller.

En otro apartado nos proponemos estudiar su obra pictórica, pues no solo por la cantidad de obras conservadas, sino también por la calidad de las mismas, Concha se nos aparece sobre todo como pintor; en seguida habría que pensar en el estudio de su obra escultórica y, en último término y siempre considerándolo de segunda categoría, quedaría quizás su calidad de arquitecto.

49 Ibidem, p. 410 